\title{
Female genital schistosomiasis as an evidence of a neglected cause for reproductive ill-health: a retrospective histopathological study from Tanzania
}

\author{
Britta Swai $^{\dagger 1}$, Gabriele Poggensee*2, Sabina Mtweve ${ }^{\dagger 3}$ and Ingela Krantz ${ }^{\dagger 4,5}$
}

Address: ${ }^{1}$ Department of Pathology, Kilimanjaro Christian Medical Centre, Moshi, Tanzania, ${ }^{2}$ Department of Infectious Disease Epidemiology, Robert Koch Institute, Seestraße 10, 13353 Berlin, Germany, ${ }^{3}$ Community Health Department, Kilimanjaro Christian Medical Centre, Moshi, Tanzania, ${ }^{4}$ Skaraborg Institute for Research and Development, Skövde, Sweden and ${ }^{5}$ Department of Public Health and Clinical Medicine, Epidemiology, Umeå University, Sweden

Email: Britta Swai - pathology@kcmc.ac.tz; Gabriele Poggensee* - poggenseeG@rki.de; Sabina Mtweve - commhealth@kcmc.ac.tz; Ingela Krantz - ingela.krantz@skaraborg-institute.se

* Corresponding author †Equal contributors

Published: 23 August 2006

BMC Infectious Diseases 2006, 6:134 doi:10.1186/147/-2334-6-134
Received: 23 February 2006

Accepted: 23 August 2006

This article is available from: http://www.biomedcentral.com/I47/-2334/6//34

(C) 2006 Swai et al; licensee BioMed Central Ltd.

This is an Open Access article distributed under the terms of the Creative Commons Attribution License (http://creativecommons.org/licenses/by/2.0), which permits unrestricted use, distribution, and reproduction in any medium, provided the original work is properly cited.

\begin{abstract}
Background: Schistosomiasis affects the reproductive health of women. Described sequelae are ectopic pregnancy, infertility, abortion, and cervical lesions and symptoms mimicking cervical cancer and STIs. There are indications that cervical schistosomiasis lesions could become cofactors for viral infection such as HIV and HPV.

Methods: In a retrospective descriptive histopathological study clinical specimens sent between 1999 and 2005 to the pathology department of a consultant hospital in Tanzania were reviewed to analyse the occurrence and features of schistosomiasis in female genital organs.

Results: During the study period, schistosomiasis was histopathologically diagnosed in 423 specimens from different organs ( $0.7 \%$ of all specimens examined in the study period), out of those $40 \%$ were specimens from female and male organs. The specimens were sent from 24 hospitals in 13 regions of mainland Tanzania. Female genital schistosomiasis was diagnosed in 125 specimens from III patients. The main symptoms reported were bleeding disorders (48\%), ulcer (I7\%), tumor $(20 \%)$, lower abdominal pain $(11 \%)$ and infertility $(7 \%)$. The majority of cases with genital schistosomiasis were diagnosed in cervical tissue (7I cases). The confirmation of cervical cancer was specifically requested for 53 women, but the diagnosis could only be verified for 13 patients $(25 \%)$, in 40 cases only severe cervical schistosomiasis was diagnosed. Vulval/labial schistosomiasis was seen in specimens from young women. Infertility was reported in four patients with schistosomiasis of the Fallopian tubes.

Conclusion: Genital schistosomiasis adds to the disease burden of women in all age groups. Pathological consequences due to the involvement of different genital organs can be damaging for the affected women. Clinical unawareness of genital schistosomiasis can lead to misdiagnosis and therefore false and ineffective therapy. In endemic areas cervical schistosomiasis should be considered as differential diagnosis of cancer.
\end{abstract}




\section{Background}

Ill-health due to reproductive health problems and sexually transmitted infections (STIs) is mostly both preventable and remediable to its nature. These illnesses, notwithstanding, account for almost one fifth of the health burden in women [1]. Many go unrecognised, since, as could be expected, the heaviest toll befalls women in the poorest countries where services are limited. Sexual and reproductive health are affected by sociocultural factors; both at individual and societal level stigmatization and shame are deeply engrained factors influencing whatever actions are taken against these diseases and their symptoms.

Although both health professionals and the public are aware of the dismal statistics for STIs, few seem to realize that there are other infectious agents than bacteria and virus that can havoc and complicate reproductive health. Symptoms and signs associated with a STI are not uncommon in schistosomiasis, a parasitic helminth disease afflicting around 250 million people, again in the poorest countries where services are limited [2]. More than is usually acknowledged schistosomiasis affects the reproductive organs of women. Female genital schistosomiasis was described for the first time in a young Egyptian woman more than 100 years ago [3], but still awaits its proper place among the public health explanatory and target factors for sexual and reproductive ill-health. Schistosomiasis and its association with ectopic pregnancy, infertility, abortion, and cervical lesions similar to STI or cervical cancer have been described in many case reports [4]. Cervical schistosomiasis causes damages of the epithelium and these lesions, if manifest before sexual debut, could become considerable co-factors for the transmission of viral infections such as HIV and HPV infections in early ages $[5,6]$.

Systematic histopathology studies made by pathologists and gynecologists in schistosomiasis endemic areas in the 1970 s and 1980s have confirmed the presence of schistosoma eggs and adult worms in upper and lower female genital organs [7-12]. The relation of schistosomiasis to cervical cancer has only rarely received attention $[13,14]$. Cervical cancer is the most common malignancy among women in African countries [15]. Since diagnosis and treatment are inadequate or non-existent even in tertiary hospitals, women often present at a hospital in an advanced and desolate stage of the disease $[16,17]$.

Tanzania belongs to the poorest countries in the world [18]. Its health care has to struggle with an overwhelming burden of diseases relying on a weak infrastructure. Infectious diseases are prominent, notably so sexually transmitted ones. STIs, including HIV, have already been seen in primary school-children, although at a low level [19].
At least one ongoing treatable reproductive tract infection was present in 64 percent of women attending urban primary healthcare facilities in the Northern Region and in 39 percent of women attending antenatal care in rural health care facilities [20,21]. Professional knowledge and awareness of female genital schistosomiasis can bring a lot to the quality of care in sexual and reproductive health.

In this article we present evidence of female genital schistosomiasis in referred specimens to a pathology department in Northern Tanzania.

\section{Methods}

The Kilimanjaro Christian Medical Centre (KCMC) is the consultant hospital for over 12 to 15 million inhabitants of Northern Tanzania. It is also the Medical College of the Tumaini University. The Department of Pathology receives biopsies and surgical specimens from over 50 hospitals all over the country, which means that they are responsible for about 35 percent of this type of examinations made in Tanzania. Around 5,000 specmines of all kinds are processed yearly.

The specimens are routinely fixed and preserved in 10 percent formaldehyde for transportation. At KCMC the tissues were paraffin-embedded. Five to $7 \mu \mathrm{m}$ thick sections are cut on a microtome and mounted onto microscope slides. The sections are stained with Hematoxylin and Eosin for the microscopical examination. Two slides are prepared and analysed from each paraffin-embedded block.

All surgical specimens sent to or taken at KCMC between 1994 and 2005 in which the histopathological diagnosis of schistosomiasis was established were reviewed. Age, provisional diagnosis and symptoms, when available, as well as all specific histopathology information were noted for the female patients where the examination had shown the presence of schistosomiasis.

\section{Ethical considerations}

This study is part of a larger project "Sustainable Prevention of Endemic Schistosomiasis" (SPES), a research collaboration between KCMC and the Skaraborg Institute for Research and Development, Skövde, Sweden. Ethical clearance was given by the Research and Ethical Committee of the KCMC, Tumaini University, Tanzania. Research data were processed and stored anonymously.

\section{Results}

During the study period (12 years) 423 organ specimens examined at Department of Pathology (equals $0.7 \%$ of the total number of specimens during this time period) had a histopathologically confirmed schistosomiasis diagnosis. In 172 cases (40.7\%) schistosomiasis was diag- 
nosed in bladder and/or urethra and/or urether specimens, in 15 cases (3.5\%) in liver specimens, in 45 cases $(10.6 \%)$ in intestine specimens (jejunum, colon, appendix, rectum) and in 8 cases $(1.9 \%)$ in mesentery/ omentum. Genital schistosomiasis was diagnosed in 176 specimens from genital organs (41.6\%: 115 organ specimens from female patients). Totally, genital specimens from 111 women were examined. The age of the patients ranged from five to 61 years, with a median age of 34 years. The specimens were sent from 24 hospitals in 13 regions of mainland Tanzania. Organs represented were peritoneum, uterus, cervix, ovary, Fallopian tubes, vagina/ vulva, perineum and labia. The specimens consisted of biopsies from in situ and removed organs. The provisional diagnosis on the referral form was mostly a suspicion of malignancy. The main symptoms reported were bleeding disorders $(48 \%)$, ulcer (17\%), tumor $(20 \%)$, lower abdominal pain (11\%), and infertility (7\%).

Eleven percent of the specimens came from women less than 20 years old. Table 1 shows the age distribution per organ examined. In 84 patients (75\%) no other diagnosis besides schistosomiasis was established.

Schistosomiasis was seen in simultaneously in two sites in 13 patients and in three sites in two patients with the following combinations, cervix and uterus; uterus and peritoneum; ovary and Fallopian tube; ovary and peritoneum; uterus, cervix and ovary. In five specimens schistosome eggs as well as adults worms were detected (labia, cervix, and ovary).

\section{Specimens from the cervix only or in combination with other organs}

Of all the 71 cervical specimens 14 (20\%) showed signs of malignancy; epithelial dysplasia (4), carcinoma in situ (2), squamous cell carcinoma (6), adenocarcinoma (1) and lymphangiosis carcinoma (1). In the rest schistosto-

Table I: Number of examined organs per age group of 105 of the I I female patients for whom age information was available. Percentages in brackets.

\begin{tabular}{|c|c|c|c|c|}
\hline \multirow[t]{2}{*}{ Specimen ${ }^{a}$} & \multicolumn{4}{|c|}{ Agegroup (years) } \\
\hline & $5-19$ & $20-29$ & $30-39$ & $\geq 40$ \\
\hline Cervix & $2(20)$ & $15(47)$ & $18(50)$ & $28(74)$ \\
\hline Uterus & $\mathrm{I}(10)$ & $5(16)$ & $5(14)$ & $7(18)$ \\
\hline Ovary & & $5(16)$ & 7 (19) & $2(5)$ \\
\hline Tubes & & $2(6)$ & $2(6)$ & I (3) \\
\hline Vagina/Vulva & & I (3) & & \\
\hline Labiab & $5(50)$ & & & \\
\hline Skin/Perineum & $2(20)$ & & & \\
\hline Peritoneum & & $4(13)$ & $4(\mathrm{II})$ & \\
\hline Total & 10 & 32 & 36 & 38 \\
\hline
\end{tabular}

a double registration possible.

b age range: $8-18$ years. somias associated with chronic inflammation was diagnosed.

For the 62 patients in this group symptoms reported were intermenstrual bleeding, post-coital bleeding, irregular menstruation, contact bleeding, and post-menopausal bleeding, with a median duration of symptoms given as four months (range 2 - 96 months). The clinical findings were described in 31 patients as suspicious appearance of the cervix (61\%), ulcer/erosion (35\%), growth/polyp $(16 \%)$, tumor $(13 \%)$, and friable/hard/nodular cervix $(13 \%)$.

The median age of the women with or without cervical malignancy was 39 years.

The verification of a provisional carcinoma diagnosis was explicitly requested for 53 patients (Table 2). The carcinoma diagnosis could be confirmed for 13 of them.

\section{Specimens from uterus/endometrium}

Three of the ten uterine specimens showed only severe schistosomiasis. Schistosomiasis was associated with leiomyoma in four specimens, and in one specimen each with adenomyosis, adenomyosis/leiomyoma, and endometritis. Seven patients had undergone total hysterectomia, in one case with right salpingo-oophorectomia. One patient (28 years) had a hysterectomia performed due to a tumor of the cervix, however, the histopathology diagnosis of this case was severe schistosomiasis of the cervix and uterus. In one patient a squamous epithelial carcinoma associated with schistosomias was diagnosed in the bladder, the right and left ureter, and the uterus. In seven specimens of the endometrium, schistosomiasis was diagnosed; in one of these cases concomitant tuberculosis could not be ruled out.

\section{Fallopian tubes/ovary/peritoneum}

This group consisted of 14 samples from ovarian tissue and five from the Fallopian tubes. Severe scarring due to schistosomiasis was seen in one case and in two cases there was a specific inflammatory reaction. In three cases schistosomiasis of the peritoneum, in one schistosomiasis of pelvic tissue, and in one schistosomiasis of a lymphnode was also noted. Infertility was reported in four patients where tubal schistosomiasis was found $(21,25$, 31 and 33 years old). A provisional diagnosis of cancer was confirmed in two out of seven women (Table 2).

\section{Labia/vulva/perineum}

Schistosomiasis of the external genital organs was only seen in girls and one young woman: vulva ( 1 case: 8 years old), perineum ( 2 cases: 5 and 6 years old) and labia (5 cases: 10, 11, 13, 13 and 18 years old). Labial tumors were 
Table 2: Results of the histopathology examination for patients with the provisional diagnosis of carcinoma on the request form.

\begin{tabular}{|c|c|c|c|}
\hline \multirow[t]{2}{*}{ Specimen } & \multirow[t]{2}{*}{ Provisional diagnosis - carcinoma } & \multicolumn{2}{|c|}{ Histological diagnosis } \\
\hline & & Carcinoma and schistosomiasis & Schistosomiasis only \\
\hline \multicolumn{4}{|l|}{ Cervix } \\
\hline Only cervix & 47 & 12 & 35 \\
\hline Cervix and uterus & 4 & & 4 \\
\hline Cervix and endometrium & 1 & & 1 \\
\hline Cervix and vagina & 1 & 1 & \\
\hline \multicolumn{4}{|l|}{ Ovary } \\
\hline Only ovary & 4 & 2 & 2 \\
\hline Ovary and uterus & 1 & & 1 \\
\hline Ovary and Fallopian tubes & 1 & & 1 \\
\hline Ovary and peritoneum & 1 & & 1 \\
\hline
\end{tabular}

reported in the request form in four cases, in two cases associated with ulcera and verrucous skin.

\section{Discussion}

Schistosomiasis is an important and highly prevalent helminthic infection related to water contact and poverty and is affecting approximately 250 million people living in the tropical and sub-tropical parts of Sub-Saharan Africa, Asia and South America [2]. The number of women with schistosomiasis-related signs and symptoms thus ought to be high and could easily concern millions. Re-assessing the world-wide clinical morbidity caused by schistosomes, however, van der Werf et al. [22] have not included the clinical picture of genital schistosomiasis in the analysis because of insufficient data. Since the first description more than 100 years ago, numerous case reports published over decades in journals of different specialities (gynaecology, pathology, urology, histology, tropical medicine) have presented clinical features - often described as unusual - of genital schistosomiasis in female patients. In 1949 Charlewood concluded by examining reports of the South African Institute of Medical Research: "...it is apparent that practically all gynaecologists who have been practising in Johannesburg and Durban for any length of time have encountered gynaecological manifestations of Bilharzia. Yet, it is surprising how meagre and unsatisfactory is the literature on the subject" [23]. The situation has not changed. Systematic research on the morbidity caused by genital involvement during the course of a schistosome infection is so far sketchy and research on the possible impact of genital schistosomiasis on viral co-infections is to our mind virtually non-existent.

Retrospective histopathology studies carried out in Egypt, Malawi, Mozambique, South Africa, Tanzania and Zimbabwe have shown that genital involvement mainly caused by Schistosoma haematobium most often occur in the vagina and cervix, less frequently in the ovary, tube and uterus. Gelfand et al. [24] found in a series of consecutive autopsies, using the sensitive digestion method, schistosome eggs in female genital organs in 58 percent of the cases. Investigations based on specimens from gynaecological surgical interventions (biopsies, curettage, organ exstirpation) can give information about the relative frequency of pathological changes in the different genital organs. In Gabon, Mozambique, Malawi and Madagaskar female genital schistosomiasis has been diagnosed in from 0.7 percent (Madagascar) up to 29 percent (Mozambique) of such genital specimens $[11,12,25,26]$. In cases of ectopic pregnancy, tubal schistosomiasis was found in Cote d'Ivoire and Gabon in 3.6 and 1.8 percent, respectively $[25,27]$. On Pemba Island in Tanzania tubal schistosomiasis was diagnosed in 39.8 percent of all cases with primary or secondary infertility [28]. In Cote d'Ivoire schistosomiasis of the placenta was diagnosed in a prospective study in 22.3 percent of 322 cases. When a subgroup of 87 of patients were examined for urinary schistosomiasis, in only 12.6 percent of the women the diagnosis of urinary schistosomiasis could be confirmed [8].

Out of the 423 cases with a histopathological confirmed diagnosis of schistosomiasis the genital and urinary involvement occurred to the same degree ( $41 \%$ and $42 \%)$. In no case a provisional diagnosis of female genital schistosomiasis was mentioned on the request forms. Whereas six percent of the cases were due to multi-focal infections in Malawi [11], we found involvement in more than one organ in 12 percent.

Genital schistosomiasis is associated with bleeding disorders, lower abdominal pain but also with infertility. A simultaneous affection of the ovaries and Fallopian tubes and/or peritoneum, as was found in our material, has been reported previously [29-31]. A high tissue egg burden is associated with generalized inflammation and 
fibrosis and thus mechanically impairs the tubal motility or the tubal patency [32-34]. Ectopic pregancies or infertility are the highly possible outcomes of this [28,35-38].

Cervical schistosomiasis as a chronic disease persisting for years causes damages of the cervical epithelium and can theoretically render the local immune environment favourable for viral infections such as caused by HIV and human papilloma virus (HPV) [5,6]. Impaired cell-mediated immunity has been shown in patients with schistosomiasis of the urinary bladder associated with carcinoma of the bladder or of the prostate [39]. Clinical evidence corroborates this hypothesis. Firstly, according to crosssectional studies carried out in schistosomiasis-endemic areas cervical involvement is common. Secondly, analysing prevalence data so far available, one can see a correlation between prevalence of urinary schistosomiasis and cervical schistosomiasis; the higher the prevalence of urinary schistosomiasis the higher the prevalence of cervical schistosomiasis (Figure 1). Thirdly, cervical schistosomiasis is associated with lesions such as sandy patches, erosion, mucosal bleeding, and abnormal blood vessels $[40,41]$. The clinical features seen in the patients of our study were cervical tumors, friable, easily bleeding cervix, and suspect appearance of the cervix. Berry [42] in an extensive series of histopathological investigations of cervical specimens, noted presence of eggs without inflammation; mild cervicitis with scattered lymphocytes, histiocytes and plasma cells, sometimes associated with atrophic epithelium; scattered eosinophils throughout the connective tissue; interstitial hemorrhage, chronic cervicitis often with ulceration. Lesions in the cervix impair the epithelial integrity and thus make it biologically plausible that schistosomiasis can increase the risk for transmission of HIV-infection in the same way as is seen in other genital ulcer disease [43]. This could of course be valid for other infectious agents with the same transmission pattern as HIV. Another memento is that the mucosal changes by schistosomiasis could already be there before the young women starts their sexual-reproductive life.

The possible association between cervical cancer and cervical schistosomiasis have been studied retrospectively by histopathology analysis. Genital schistosomiasis was diagnosed in 1.7, 1.9 and 3.0 percent of cases with cervical cancer in three studies from Malawi and Tanzania $[11,13,14]$. In all the studies the percentage of cervical schistosomiasis detected in cervical tissue without cervical cancer was higher $(4.3 \%, 6.0 \%, 9.8 \%)$. A possible explanation for these findings is the fact that the clinical features of cervical schistosomiasis simulate those produced by malignancy. The results of our study point in this direction: the provisional diagnosis of cervical cancer in patients with genital schistosomiasis could be confirmed in only 20 percent of the patients. As a consequence women might undergo surgery such as hysterectomy on false clinical premises, which we saw in our study. The studies carried out so far cannot support the hypothesis of cervical schistosomiasis being a co-factor to HPV infection for the development of cancer. It has, however, been brought forward that chronic cervical inflammation and parasitic infection impairing the cellular immunity might contribute to the high prevalence of HPV types other than HPV16 seen in sub-Saharan Africa [44]. Petry et al. [45] showed that the HPV prevalence of patients orignating from endemic areas in Tanzania and from German controls were similar $(34.5 \%$ versus $26.9 \%)$, however, women with a history suggestive for schistosomiasis and/ or active schistosomiasis had a higher risk for habouring high risk HPV types. The authors concluded that the infection with S. haematobium sems to favor persistent genital HPV infection either by traumatizing the general epithelium and/or by local immunosuppression. Additionally, the interplay of HIV, schistosomiasis and HPV might very well have an impact on HPV infection. Reporting two cases of HIV-positive women with schistosomiasis of the cervix Prabhakaran and Brown [46] proposed timely treatment against schistosomiasis to prevent aggressive HPV infection and its consequences in HIV-infected patients. The authors argue that persistent schistosomiasis may result in earlier HPV relapses because schistosomiasis increases the likelikhood of STDs. Recently, two cases of cervical schistosomiasis and squamous cell carcinoma have been reported in which high-risk HPV could not be detected [47], however, with the low number of specimens the possibilty of false negative test results and/or insuffienct conservation have to be considered as alternative explanation [48]. Another possible patho-mechanism might be the inactivation of tumor suppressor genes. Mutations of the p53 tumor suppressor gene which encodes a protein involved in the growth and regulation of cells and of components of the DNA damage control response is one of the most frequent genetic alteration in a variety of malignancies. Mutations in the tumor suppressor gene p53 have been observed more frequently in patients with schistosomiasis-associated bladder cancer compared to patients with non-schistosomiasis associated bladder cancer [49].

\section{Conclusion}

The retrospective histopathological data presented give an overview of the occurrence of schistosomiasis in genital organs in women living in a schistosomiasis endemic area. Conclusions on the prevalence of female genital schistosomiasis in the different genital organs can not be drawn from this type of study. However, the results indicate that genital schistosomiasis has to be considered as differential diagnosis in a schistosomiasis endemic areas. Genital schistosomiasis misdiagnosed as cancer can be detrimental and devastating, if surgery is done. Further- 


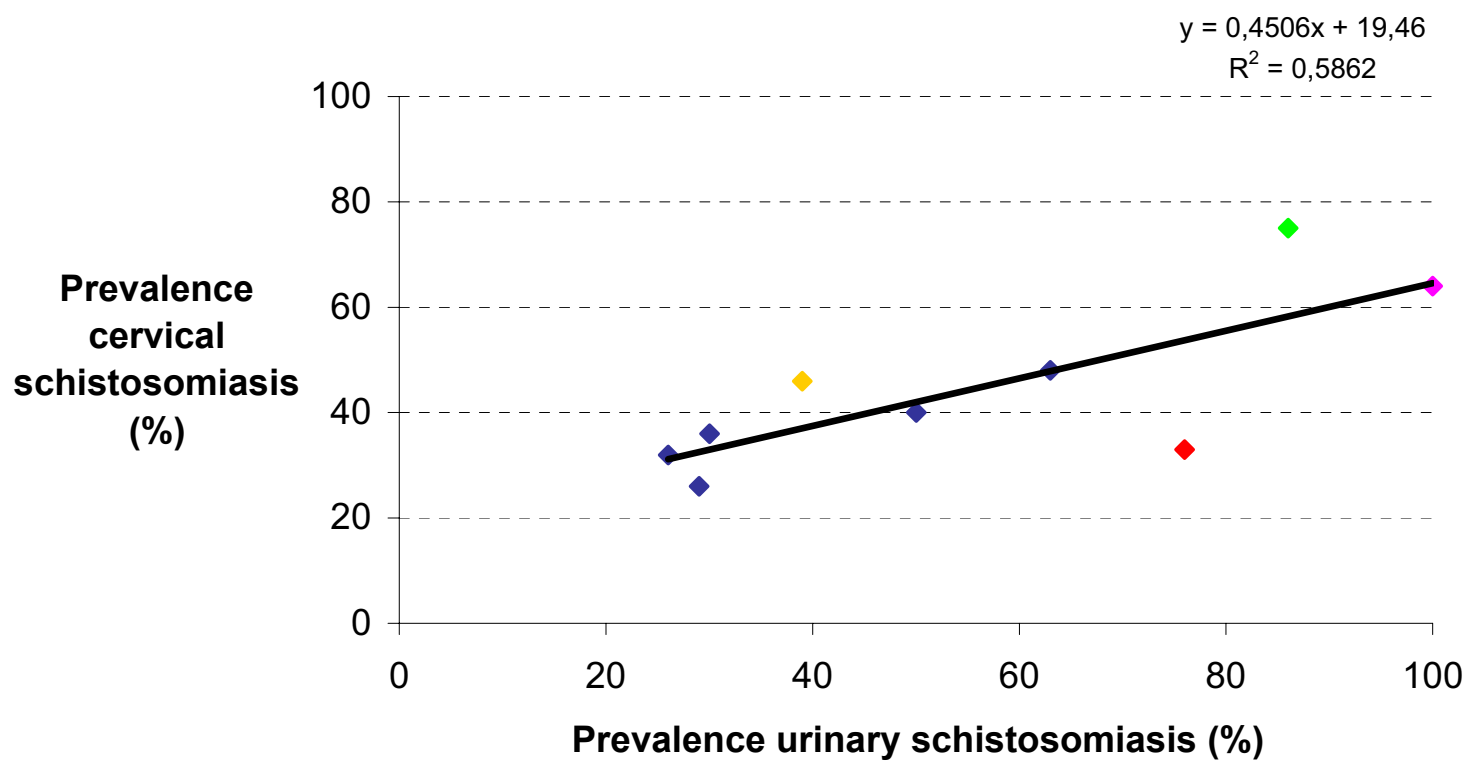

Blue dots: Tanzania, community-based studies, diagnosis by biopsy (five villages, total $n=460$ ) (unpublished data) [40]

Red dot: Madagascar, community-based study, diagnosis in sub-group of study participants by biopsy ( $\mathrm{n}$ = 36) [50]

Green dot: Niger, community-based study, diagnosis by biopsy $(n=61)$ [51]

Pink dot: Malawi, hospital-based study, diagnosis by biopsy, only women with urinary schistosomiasis included $(n=51)$ [52]

Yellow dot: Zimbabwe, community-based study, diagnosis on clinical grounds $(n=527)$ [41]

\section{Figure I}

Combined analysis of data from five schistosomiasis-endemic countries. Relation between prevalence of urinary schistosomiasis and the occurrence of genital schistosomiasis of the cervix uteri in women with urinary schistosomiasis.

more, cervical genital schistosomiasis misdiagnosed as an STI can lead to ineffective treatment. Schistosome-, HIVand HPV-infections are highly prevalent in sub-Saharan Africa, indications that cervical schistosomiasis can influence the course of STIs are at hand.

\section{Competing interests}

The author(s) declare that they have no competing interests.

\section{Authors' contributions}

BS participated in the collection of data, interpretation fo findings and the drafting of the manuscript. GP participated in the analysis, the interpretation, the presentation of findings and the preparation of the manuscript. SM participated in the interpretation of the results. IK participated in the interpretation of the findings and the preparation of the manuscript. All authors read and approved the final manuscript. 


\section{Acknowledgements}

We are grateful for the continuous encouragement and support of Professor Dr. John Shao, Provost of the Tumaini University, Tanzania, for the research on schistosomiasis. Sida/SAREC is the main sponsor of the SPES project (Sustainable Prevention of Endemic schistosomiasis).

\section{References}

I. Alan Guttmacher Institute: Into a new world: young women's sexual and reproductive lives. New York, Alan Guttmacher Institute; 1998.

2. Chitsulo L, Engels D, Montresor A, Savioli L: The global status of schistosomiasis and its control. Acta Trop 2000, 77:5I-5I.

3. Madden FC: A case of bilharzia of the vagina. Lancet 1899 , i: $1716-1716$

4. Feldmeier H, Poggensee G, Krantz I, Helling-Giese G: Female genital schistosomiasis. New challenges from a gender perspective. Trop Geograph Med 1995, 47:I-I5.

5. Feldmeier H, Krantz I, Poggensee G: Female genital schistosomiasis - a risk factor for transmission of HIV. Int J STD AIDS 1994, 5:368-372.

6. Feldmeier H, Poggensee G, Rohrbach C, de Aguiar Patricio MA, Nogueira Queiroz JA: Female genital schistosomiasis and Human Papilloma Virus (HPV) infection: a dangerous relationship. Virus Reviews and Research 1997, 2:119-121.

7. Gelfand M, Ross MD, Blair DM, Weber MC: Distribution and extent of schistosomiasis in female pelvic organs, with special reference to the genital tract, as determined at autopsy. Am J Trop Med Hyg 197I, 20:846-849.

8. Renaud R, Brettes P, Castanier C, Loubiere R: Placental Bilharziasis. Int J Gynecol Obstet 1972, I 0:24-33.

9. Edington GM, Nwabuebo I, Junaid TA: The pathology of schistosomiasis in Ibadan, Nigeria with special reference to the appendix, brain, prancreas and genital organs. Trans Roy Soc Trop Med Hyg 1997, 69:153-162.

10. van Raalte JA, Venkataramaiah NR, Shaba JK: Bilharziasis of the female genital tract in Tanzania. East Afr Med J 1981, 58:543-547.

II. Wright ED, Chiphangwi J, Hutt MSR: Schistosomiasis of the female genital tract. A histopathological study of 176 cases from Malawi. Trans R Soc Trop Med Hyg 1982, 76:822-829.

12. Elling D, Kupferschmidt HG: Genitale Schistosomiose - Diagnostik und Therapie. Zbl Gynäkol 1988, I 10:67 I-676.

13. Moubayed P, Ziehe A, Peters J, Mwakyoma H, Schmidt D: Carcinoma of the uterine cervix associated with schistosomiasis and induced by human papillomaviruses. Int J Gynecol Obstet 1995, 49:175-179.

14. Riffenburgh RH, Olson PE, Johnstone PA: Association of schistosomiasis with cervical cancer: detecting bias in clinical studies. East Afr Med J 1997, 74: |4-16.

15. Parkin DM: Cancer in developing countries. Cancer Surv 1994, | 9-20:519-561.

16. Ngwalle EW, Mgaya HN, Mpanju-Shumbusho W, Chirenje ZM, Kirumbi L, Lebelle T, Kaggwa S: Situational analysis for diagnosis and treatment of cervical cancer in mainland Tanzania. East Afr Med J 200I, 78:60-64.

17. Kidanto HL, Kilewo CD, Moshiro C: Cancer of the cervix: knowledge and attitudes of female patients admitted at Muhimbili National Hospital, Dar es Salaam. East Afr Med J 2002, 79:467-75.

18. CIA.The World Fact Book. Tanzania (updated 22. August 2006) [https://www.cia.gov/cia/publications/factbook/geos/ tz.html\#|ntro]

19. Todd J, Changalucha J, Ross DA, Mosha F, Obasi AIN, Plummer M, Balira R, Grosskurth H, Mabey DCW, Hayes R: The sexual health of pupils in years 4 to 6 of primary schools in rural Tanzania. Sex Transm Inf 2004, 80:35-42.

20. Mayaud P, Grosskurth H, Changalucha J, Todd J, West B, Gabone R, Senkoro K, Rusizoka M, Laga M, Hayes R: Risk assessment and other screening options for gonorrhoea and chlamydial infections in women attending rural Tanzanian antenatal clinics. Bull WHO 1995, 73:621-30.

21. Msuya SE, Mbizvo E, Stray-Pedersen B, Sundby J, Sam NE, Hussain A: Reproductive tract infections and the risk of HIV among women in Moshi, Tanzania. Acta Obstet Gynecol Scand 2002, 81:886-893.
22. Van der Werf MJ, de Vlas SJ, Brooker S, Looman CWN, Nagelkerke NJD, Habbema JDF, Engels D: Quantification of clinical morbidity associated with schistosome infection in sub-Saharan Africa. Acta Trop 2003, 86: I25-139.

23. Charlewood GP, Shippel S, Renton H: Schistosomiasis in gynaecology. J Obstet Gynaecol 1949, 56:367-385.

24. Gelfand $M$, Ross MD, Blair DM, Weber MC: Distribution and extend of schistosomiasis in female pelvicc organs, with special reference to the genital tract, as determined at autopsy. Am J Trop Med Hyg I 97I, 20:846-849.

25. Ville Y, Leruez M, Picaud A, Walter P, Fernandez H: Tubal schistosomiasis as a cause of ectopic pregnancy in endemic areas? a report of three cases. Europ J Obstet Gynecol Reprod Biol 1991, 42:77-79.

26. Brygoo ER: Les bilharzioses humaines à Madagascar. In Extrait de la santé et développement Antananario; 1968.

27. Loubière R: La bilharziose en Côte d'Ivoire. Med Afr N 1977 , 24:453.

28. Scheller R: Genitalbilharziose und Extrauteringravidität. Z $\mathrm{bl}$ Gynäkol 1974, 96:88-92.

29. El-Mahgoub S: Pelvic schistosomiasis and infertility. Int J Gynecol Obstet 1982, 20:201-206.

30. Mouktar M: Functional disorders due to bilharzial infection of the female genital tract. J Obstet Gynaec Brit Cwlth 1966, 73:307-310.

31. Nosny Y: La bilharziose génito-urinaire. Bull Soc Pathol Exot 1963, 56:999-1048.

32. Berg J: Bilharziosis of the female sexual organs. Zentralb/ Gynakol 1972, 94:673-677.

33. Hoffmann $\mathrm{H}$, Bauerfeind I: High tissue egg burden mechanically impairing the tubal motility in genital schistosomiasis of the female. Acta Obstet Gynecol Scand 2003, 82:970-97I.

34. Letterie GS, Sakas L: Proximal tubal obstruction associated with tubal schistosomiasis. Int J Gynecol Obstet 1992, 37:293-296.

35. Bughalo A, Strolego F, Benussi G, Pregazzi R, Osamn N: Schistosomiasis possibile case di gravidanza ectopica. Minerva ginecol 1991, 43:577-579.

36. Nouhou PH, Mossi A: Aspects anatomopathologiques de vingtcinq cas de cancers "bilharziens" de la vessie. Bull Soc Pathol Exot 1996, 89:181-184.

37. Okonofua FE, Ojo OS, Odunsi OA, Odesanmi WO: Ectopic pregnancy associated with tubal schistosomiasis in a Nigerian woman. Int J Gynecol Obstet 1990, 32:28I-284.

38. Picaud A, Walter P, Bennani S, Minko Mi ED, Nlome Nze AR: Fallopian tube bilharziasis caused by Schistosoma intercalatum disclosed by hemoperitoneum. Arch Anat Cytol Pathol 1990, 38:208-2II.

39. Raziuddin S, Shetty S, Ibrahim A, Patil K: Activated CD4-positive T-lymphocytes and impaired cell-mediated immunity in patients with carcinoma of the urinary bladder with schistosomiasis. Cancer 1990, 65:931-939.

40. Poggensee G, Kiwelu I, Weger V, Göppner D, Diedrich T, Krantz I, Feldmeier $\mathrm{H}$ : Female genital schistosomiasis of the lower genital tract: prevalence and disease-associated morbidity in northern Tanzania. J Infect Dis 2000, I 8 I: I 2 I0-12 I3.

4I. Kjetland EF, Ndholovu PD, Mduluza T, Gomo E, Gwanzura L, Mason PR, Kurewa EN, Midzi N, Friis H, Gundersen SG: Simple clinical manifestations of genital Schistosoma haematobium infection in rural Zimbabwean women. Am J Trop Med Hyg 2005, 72:311-319.

42. Berry A: A cytopathological and histopathological study of bilharziasis of the female genital tract. J Path Bact 1966, 91:325-338.

43. Laga M, Manoka A, Kivuvu M, Malele B, Tuliza M, Nzila N, Goeman J, Behets F, Batter V, Alary M: Non-ulcerative sexually transmitted diseases as risk factors for HIV-I transmission in women: results from a cohort study. AIDS 1993, 7:95-102.

44. Clifford GM, Gallus S, Herrero R, Muoz N, Snijders PJF, Vaccarella S, Anh PTH, Ferreccio C, Hieu NT, Matos E, Molaana M, Rajkumar R, Ronco G, de Sanjosé S, Shin HR, Sukvirach S, Thmas JO, Tunsakul S, Meijer CJLM, Franceschi S, and the IARC HPV Prevalence Surveys Study Group: Worldwide distribution of human papillomavirus types in cytologically normal women in the International Agency for Research on Cancer HPV prevalence surveys: a pooled analysis. Lancet 2005, 366:991-998. 
45. Petry KU, Scholz U, Hollwitz B, Von Wasielewski R, Meijer C): Human papillomavirus, coinfection with Schistosoma haematobium, and cervical neoplasia in rural Tanzania. Int J Gynecol Cancer 2003, I 3:505-509.

46. Prabhakaran VC, Brown LJR: Cervical schistosomiasis and neoplasia in HIV-infected patients. Int J Gynecol Pathol 2004, 23:403-404.

47. North M, Dubinchik I, Hamid A, Elderiny S, Sayegh R: Association between cervical schistosomiasis and cervical cancer. J Reprod Med 2003, 48:995-998.

48. Böhmer G, van den Brule AJC, Brummer O, Meijer CJLM, Petry KU: No confirmed case of human papillomavirus DNA-negative cervical intraepithelial neoplasia grade 3 or invasive primary cancer of the uterine cervix among $5 \mathrm{I} I$ patients. Am J Obstet Gynecol 2003, I 89: I I8-I 20.

49. Mostafa MH, Sheweita SA, O'Connor PJ: Relationship between schistosomiasis and bladder cancer. Clinical Microbiol Review 1999, I 2:97-III.

50. Leutscher $P$, Ravaoalimalala VE, Raharisolo $C$, Ramarokoto $C E$, Rasendramino M, Raobelison A, Vennervald B, Esterre P, Feldmeier $\mathrm{H}$ : Clinical findings in female genital schistosomiasis in Madagascar. Trop Med Int Health 1998, 3:327-332.

51. Renaud D, Devidas A, develoux M, Lamothe F, Bianchi G: Prevalence of vaginal schistosomiasis due to Schistosoma haematobium in an endemic village in Niger. Trans $R$ Soc Trop Med 1989, 83:797.

52. Kjetland EF, Poggensee G, Helling-Giese G, Richter J, Sjaastad A, Chitsulo L, Kumwenda N, Gundersen SG, Krantz I, Feldmeier H: Female genital schistosomiasis due to Schistosoma haematobium. Clinical and parasitological findings in women in rural Malawi. Acta Trop 1996, 62:239-255.

\section{Pre-publication history}

The pre-publication history for this paper can be accessed here:

http://www.biomedcentral.com/1471-2334/6/134/pre

pub

Publish with Biomed Central and every scientist can read your work free of charge

"BioMed Central will be the most significant development for disseminating the results of biomedical research in our lifetime. "

Sir Paul Nurse, Cancer Research UK

Your research papers will be:

- available free of charge to the entire biomedical community

- peer reviewed and published immediately upon acceptance

- cited in PubMed and archived on PubMed Central

- yours - you keep the copyright

Submit your manuscript here:

http://www.biomedcentral.com/info/publishing_adv.asp
BioMedcentral 